\title{
Imaging Features of Intracranial Meningiomas with Histopathological Correlation: A Relook into Old Disease
}

\author{
Gangadhar K ${ }^{1}$, Santhosh $D^{2}$, Fatterpekar GM $^{3}$ \\ ${ }^{1}$ Plainsboro, New Jersey, NJ 08536, ${ }^{2}$ Department of Pathology, Institute of Medical Sciences, \\ Banaras Hindu University, Varanasi, India, ${ }^{3}$ NYU Langone Medical Center, New York, NY \\ 20016
}

\begin{abstract}
Background and Purpose: Imaging characteristics of meningiomas have been discussed previously in many studies; however complete imaging features involving general features, MRS and DWI of both typical and atypical meningiomas have been discussed in very few studies. CT and MR imaging findings in 46 cases of intracranial meningioma are reviewed to define specific imaging features. Methods: The present study was carried on 46 patients in the Department of Radiodiagnosis and Imaging, Institute of Medical Sciences, Banaras Hindu University during June 2009 to July 2011.The investigation was carried out by GE-VCT 64 Slice Scanner machine and Magnetic resonance imaging was contemplated using 1.5 Tesla SIEMENSMAGNETOM AVANTO. CT and MR imaging studies were reviewed to characterize mass location, imaging characteristics, atypical features and advanced imaging features. Clinical presenting signs and symptoms were correlated with imaging findings. Results: a). Forty six cases of intra cranial meningiomas were studied prospectively in 24 women and $22 \mathrm{men}$, aged 11 - 80 years. Meningiomas were stratified into typical and atypical and also depending upon intra cranial location. b). $73.91 \%$ of the cases in showed supratentorial location, rest were infratentorial (26.08\%).CT/MRI revealed well defined margins in $84.78 \%$ with homogenous consistency in $73.91 \%$ of lesions. Foci of necrosis were noted in $32.60 \%$ of cases and $15.22 \%$ of cases showed calcification foci in meningioma. Sinus invasion noticed in $15.22 \%$ of cases, whereas adjacent bony reaction noticed in $30.43 \%$ of cases. c). Majority of Meningioma showed broad dural base $(89.10 \%)$, adjacent white matter buckling $(71.74 \%)$ and surrounding CSF cleft (52.17\%). Displaced subarachnoid vessels were demonstrated in $30.43 \%$, where as the pathognomonic dural tail was present in only $23.91 \%$ of the cases. d). All the cases of Meningioma demonstrated restriction on diffusion weighted sequences suggestive of high cellularity of the lesions. On CT angiography, neovascularity was noticed in $85.71 \%$ and tumor blush was noticed in $71.42 \%$ incidence. On MR Spectroscopy, all demonstrated choline peak and in one third cases alanine peak was discernible. Conclusion: In view of the observed evidence, it was concluded that understanding the classification, pathology and imaging appearance meningioma are essential for treatment planning. CT and MR imaging play indispensable role in the localization \& characterization of these tumors, and MR have virtually yielded its position of dominance in characterizing these tumors.
\end{abstract}




\section{Introduction}

Meningiomas are the most common nonglial primary tumors of the central nervous system and the most common extraaxial neoplasms, accounting for approximately $15 \%$ of all intracranial tumors. Symptomatic meningiomas occur two to three times more commonly in female patients, especially those in the middle age (40-60 years) group, and generally are benign neoplasms that are derived from meningothelial cells. ${ }^{1}$ Meningiomas typically occur as extraaxial tumors although they are generally benign tumors, up to $10 \%$ of meningiomas are atypical or malignant, characterized by nuclear disorganization, necrosis, prominent nucleoli, and increased mitoses on histology(s).

Imaging has an important role in characterizing these lesions and helping in presurgical differential diagnosis, which is essential for optimizing treatment strategies. We will discuss these features with correlation to pathology and advanced imaging features in this article.

\section{Materials and Methods}

A prospective study of 46 patients, approved by our institutional thesis board, was evaluated with histologically correlation in patients between age group 11-80 years during a 2-year period from June 2009 to July 2011.

CT Scan was carried out by GE-VCT 64Slice Scanner machine with stand CT protocol for head and neck. Non ionic contrast media was routinely administered in all patients to look for the enhancement pattern and characteristics. Magnetic resonance imaging was contemplated using 1.5 Tesla SIEMENS-MAGNETOM AVANTO with dedicated Radio Frequency receive only head coils using following sequences T1-weighted, T2-weighted, FLAIR, Diffusion Weighted and MR spectroscopy. After these sequences were obtained, intravenous contrast study was performed in all the patients to look for the degree and the pattern of enhancement and to assess the vascularity.The $\mathrm{CT}$ and MR scans were evaluated with respect to the following points: Location (supra/infratentorial) and site of the lesion, Perifocal Edema, Intensity compared to grey matter, Contrast enhancement and type of enhancement, Presence of extraaxial signs viz, CSF cleft, displaced subarachnoid vessels, buckling of cortical gray matter between the mass and the white matter, displaced and expanded subarachnoid space, broad dural base and bony reaction, Presence of Mass effect, Presence of signal voids on T1WI and T2WI (calcification / fibrosis / vessels), Presence of Hemorrhage, Heterogeneity, Presence of Necrosis / Cystic change, Presence of calcifications, Margins: Sharp \& well defined or Ill-defined and Histology (wherever available)The evaluation data, as mentioned above, were analyzed for the summation of the present prospective study.

\section{Results}

Majority of the patients having Meningioma were female $(52.17 \%)$, while $47.82 \%$ were males. The age distribution of Meningioma revealed maximum incidence in the fourth decade $(30.43 \%)$ followed by sixth decade $(17.89 \%)$ and seventh decade (15.22\%). Majority of the cases having Meningioma involved parasaggital, CP angle (fig. 1), and sphenoid and petrous regions (15.27\% each), followed by involvement of fronto-parietal $(10.87 \%)$. Less common sites were parietal, tempero-parietal and occipital regions. 

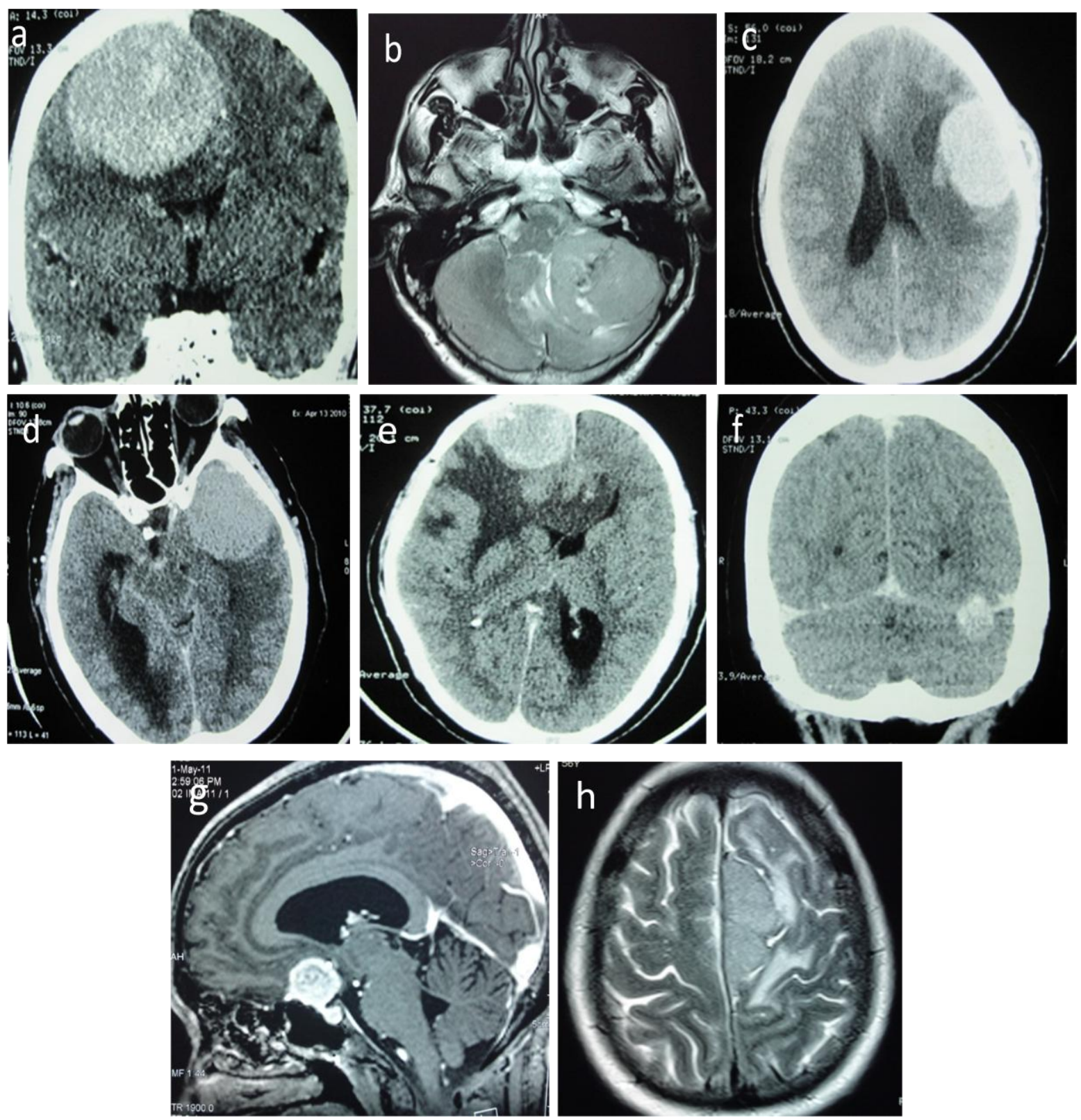

Fig 1: Locations of meningioma: a) coronal CECT showing parasaggittal location, b) left cerebellopontine angle, c) axial CECT showing left parieto-frontal location, d) axial CECT showing left temporal location, e) axial CECT showing right frontal location, f) axial CECT showing tentorial location, g) saggital post contrast T1W imaging showing sphenoid location and h) axial T2W imaging showing saggital location.

Majority of the cases (73.91\%) showed supratentorial location, rest were infratentorial $(26.08 \%)$ Meningioma. Majority of cases showed well defined margins $(84.78 \%)$ with homogenous lesions $(73.91 \%)$. Foci of necrosis were noted in $32.60 \%$ of cases and $15.22 \%$ of cases showed calcification foci. Sinus invasion noticed in $15.22 \%$ of cases, where as adjacent bony reaction noticed in $30.43 \%$ of cases (Table 1). Most of cases demonstrated homogenous enhancement of the mass $(82.61 \%)$, where as $13.04 \%$ of cases showed heterogenous enhancement and $4.35 \%$ showed ring enhancement. Two third of cases showed intense enhancement 
$(63.04 \%)$, where as $30.43 \%$ showed moderate enhancement. Two third of the cases showed peritumoral edema in adjacent brain parenchyma $(65.1 \%)$ (Table1). On CT, majority appeared as isodense or hyperdense to adjacent brain. On T1 weighted MRI, majority of the lesions appeared as isointense to adjacent grey matter and on T2 weighted majority appeared as mildly hyperintense lesions.

Table 1: Imaging Findings in Meningioma in Present Study $(\mathrm{N}=46)$ :

\begin{tabular}{|l|l|l|}
\hline Features & $\begin{array}{l}\text { No. of } \\
\text { cases }\end{array}$ & \% \\
\hline -Location: & & \\
\hline Supratentorial & 34 & $\mathbf{7 3 . 9 1}$ \\
\hline Infratentorial & 12 & $\mathbf{2 6 . 0 8}$ \\
\hline -Tumor margin: & & \\
\hline Well defined & 39 & $\mathbf{8 4 . 7 8}$ \\
\hline Ill defined & 7 & $\mathbf{1 5 . 2 2}$ \\
\hline -Mass characteristics: & & \\
\hline Homogenous & 34 & $\mathbf{7 3 . 9 1}$ \\
\hline Heterogenous & 12 & $\mathbf{2 6 . 0 8}$ \\
\hline Necrosis & 15 & $\mathbf{3 2 . 6 0}$ \\
\hline Prominent vessels & 29 & $\mathbf{6 3}$ \\
\hline Calcification & 7 & $\mathbf{1 5 . 2 2}$ \\
\hline $\begin{array}{l}\text { Dural } \\
\text { invasion }\end{array}$ & 7 & $\mathbf{1 5 . 2 2}$ \\
\hline Bony reaction & 14 & $\mathbf{3 0 . 4 3}$ \\
\hline Peritumoral edema & 30 & $\mathbf{6 5 . 1}$ \\
\hline -Enhancement: & & \\
\hline Homogenous & 38 & $\mathbf{8 2 . 6 1}$ \\
\hline Heterogenous & 6 & $\mathbf{1 3 . 0 4}$ \\
\hline Ring & 2 & $\mathbf{4 . 3 5}$ \\
\hline $\begin{array}{l}\text {-Degree } \\
\text { enhancement: }\end{array}$ & & \\
\hline Mild & 3 & $\mathbf{6 . 5 2}$ \\
\hline Moderate & 14 & $\mathbf{3 0 . 4 3}$ \\
\hline \hline Intense & $\mathbf{2 9}$ & $\mathbf{6 3 . 0 4}$ \\
\hline
\end{tabular}

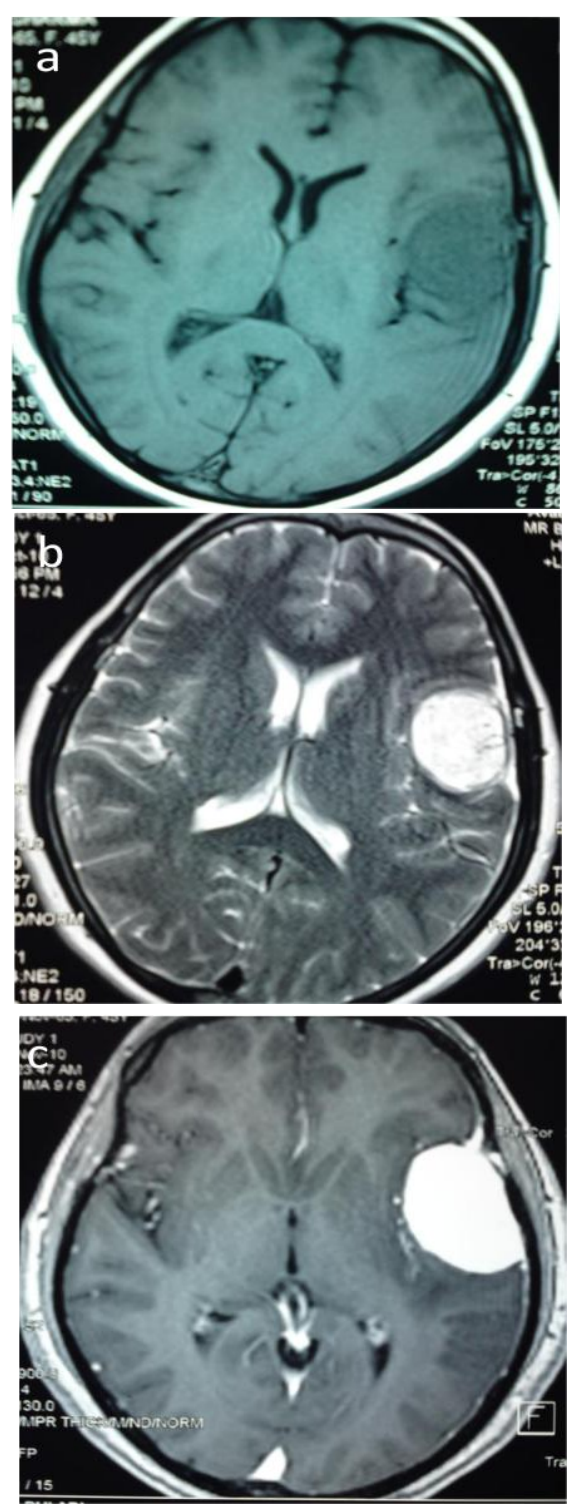

Fig 2: Typical MR imaging features. a) Axial T1W imaging showing iso/hypo intense lesion, b) axial $\mathrm{T} 2 \mathrm{~W}$ imaging showing hyper intense lesion c) axial post contrast T1W imaging showing intense homogeneous contrast enhancement.

Majority of the cases of Meningioma showed broad dural base ( $89.10 \%)$, adjacent white matter buckling $(71.74 \%)$ and surrounding CSF cleft (52.17\%). Displaced subarachnoid vessels were demonstrated in $30.43 \%$, where as the pathognomonic dural tail was present in only $23.91 \%$ of the cases (Table 2). 

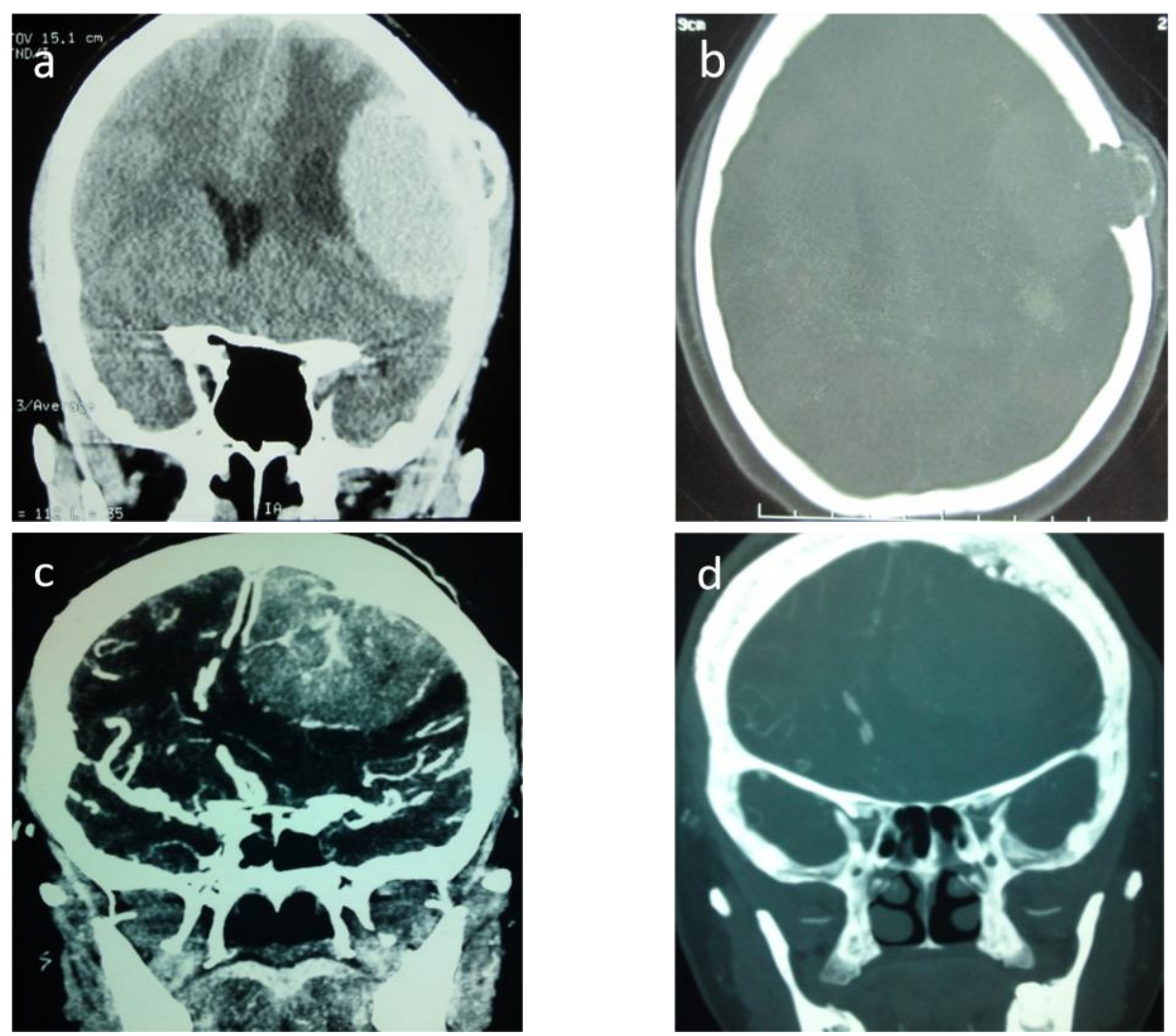

Fig 3: Bony Reaction in meningioma. Fig a) and Fig b) showing bony destruction and Fig c) and Fig d) showing hyperostosis.
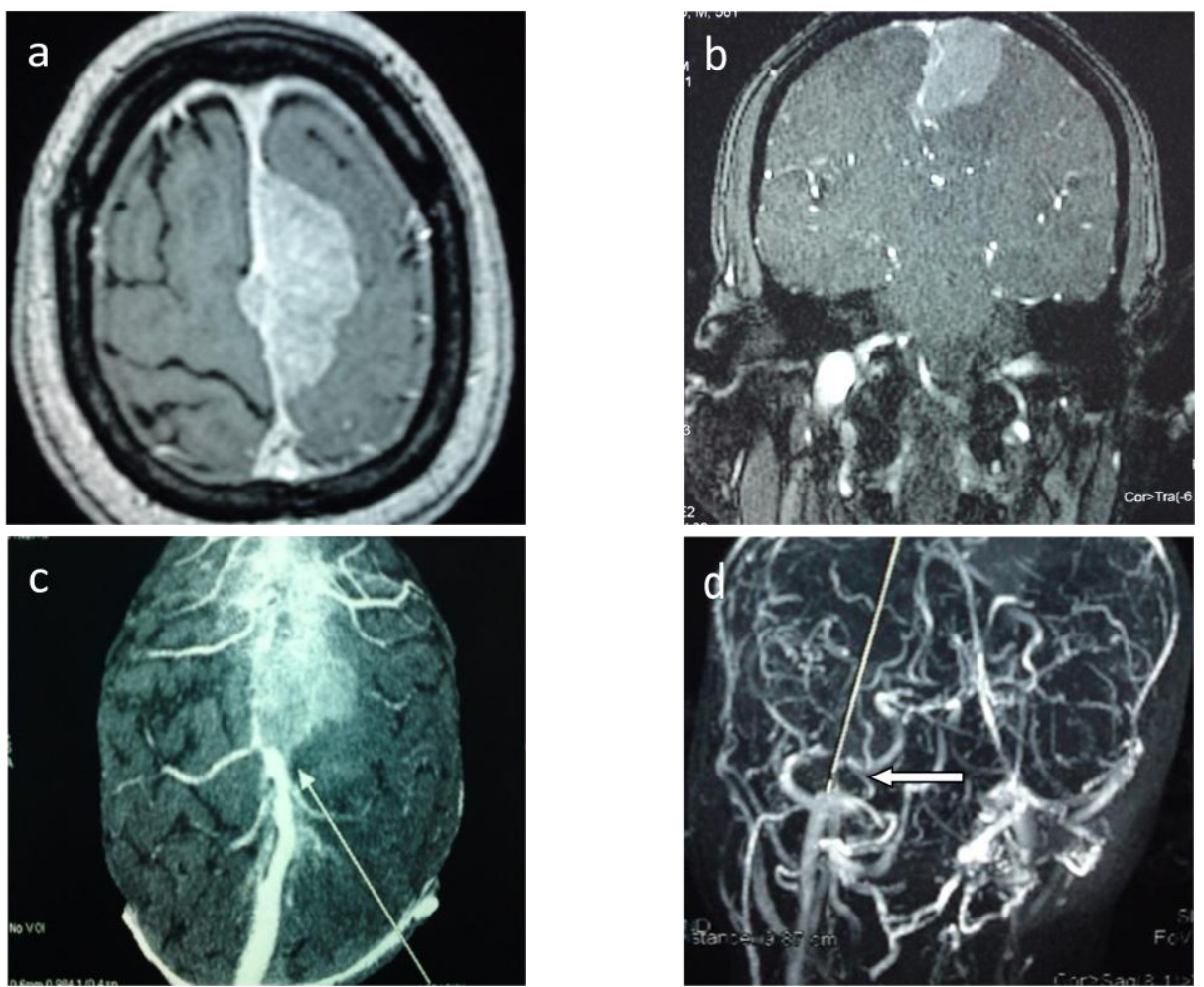

Fig 4: Sinus invasion of meningiomas. Fig a) axial T1W post contrast imaging showing saggital meningioma invading saggital dural sinus shown evidently on 2D TOF MR angiogram (Fig b), Fig c) CT angiography showing mid-saggital sinus invasion (arrow). Fig d) 3D TOF MR venography showing posterior two third saggital sinus non-visualisation with length of involvement shown with straight line (arrow). 
Table 2: Extraaxial signs displayed by Meningiomas on MR study $(\mathrm{N}=46)$ :

\begin{tabular}{|lll|}
\hline Features & $\begin{array}{l}\text { No. of } \\
\text { cases }\end{array}$ & $\%$ \\
\hline $\begin{array}{l}\text { White matter } \\
\text { buckling }\end{array}$ & 33 & $\mathbf{7 1 . 7 4}$ \\
\hline $\begin{array}{l}\text { Signal void } \\
\text { pseudocapsule }\end{array}$ & 9 & $\mathbf{1 9 . 5 6}$ \\
\hline CSF cleft & 24 & $\mathbf{5 2 . 1 7}$ \\
\hline Dural tail & 11 & $\mathbf{2 3 . 9 1}$ \\
\hline $\begin{array}{l}\text { Displaced } \\
\text { subarachnoid vessels }\end{array}$ & 14 & $\mathbf{3 0 . 4 3}$ \\
\hline \hline Broad dural base & $\mathbf{4 1}$ & $\mathbf{8 9 . 1 0}$ \\
\hline
\end{tabular}
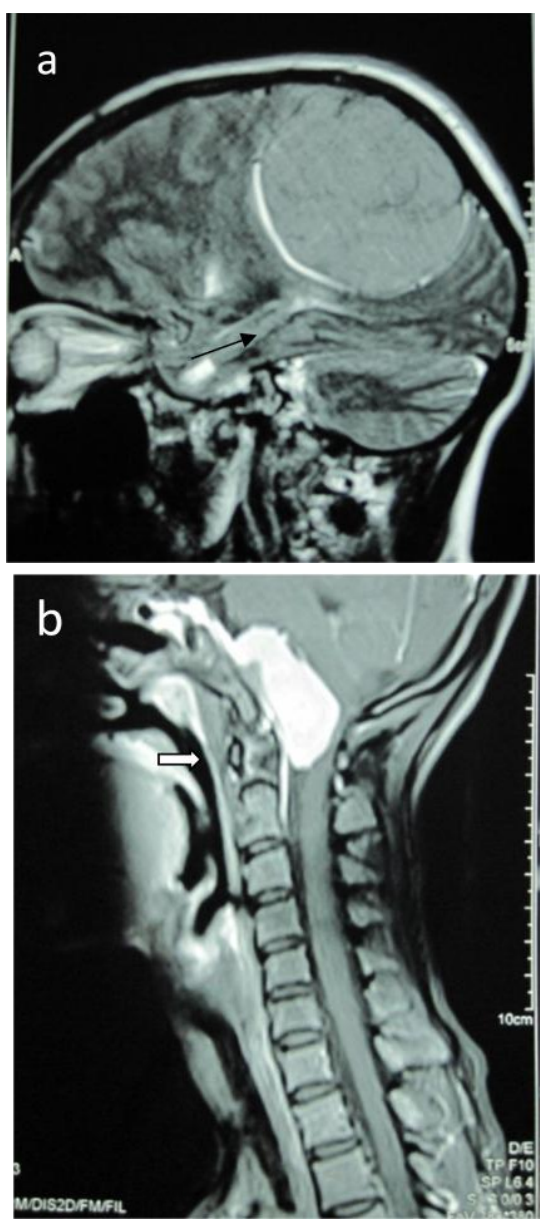

Fig 5: Typical extra axial features of meningioma. a) Saggital T2 weighted MR imaging showing broad dural base and surrounding CSF cleft (arrow). b) Saggital T1 weighted post contrast MR imaging showing broad dural base and dural tail (open arrow).
Table 11: Advanced imaging features of Meningioma in present study $(\mathrm{N}=46)$ :

\begin{tabular}{|c|l|l|}
\hline \multicolumn{3}{|c|}{$\begin{array}{l}\text { No. of } \% \\
\text { cases }\end{array}$} \\
$\begin{array}{l}\text { Diffusion } \\
\text { restriction }\end{array}$ & 9 & 100 \\
\hline -Angiography & & \\
\hline Neovascularity & 6 & $\mathbf{8 5 . 7 1}$ \\
\hline Tumour blush & 5 & 71.42 \\
\hline Sinus invasion & 7 & 100 \\
\hline -MR Spectroscopy & & 100 \\
\hline Choline peak & 3 & 33.33 \\
\hline \hline Alanine peak & 1 & \\
\hline
\end{tabular}

All the cases of Meningioma demonstrated restriction on diffusion weighted sequences suggestive of high cellularity of the lesions. On angiography, neovascularity was noticed in $85.71 \%$ and tumor blush was noticed in $71.42 \%$ incidence (Table 11) (fig. 3). On MRS, all demonstrated choline peak (100\%) and in $33.33 \%$ of cases alanine peak was discernible.

Table 3: Atypical features of Meningioma in present study:

\begin{tabular}{|l|l|l|} 
Features & $\begin{array}{l}\text { No. } \\
\text { of } \\
\text { cases }\end{array}$ & $\%$ \\
\hline Cystic changes & 6 & $\begin{array}{l}\mathbf{1 3 . 0} \\
\mathbf{4}\end{array}$ \\
\hline Ring enhancement & 2 & $\mathbf{4 . 3 4}$ \\
\hline Hypercalcification & 4 & $\mathbf{8 . 6 9}$ \\
\hline $\begin{array}{l}\text { Intra ventricular } \\
\text { location }\end{array}$ & $\mathbf{4}$ & $\mathbf{8 . 6 9}$ \\
\hline
\end{tabular}

Among atypical features demonstrated by Meningiomas, cystic changes were present in $13.04 \%$ of the cases. Hyper calcification and Intraventricular location were noted in $8.69 \%$ of cases (Table 3 ). 

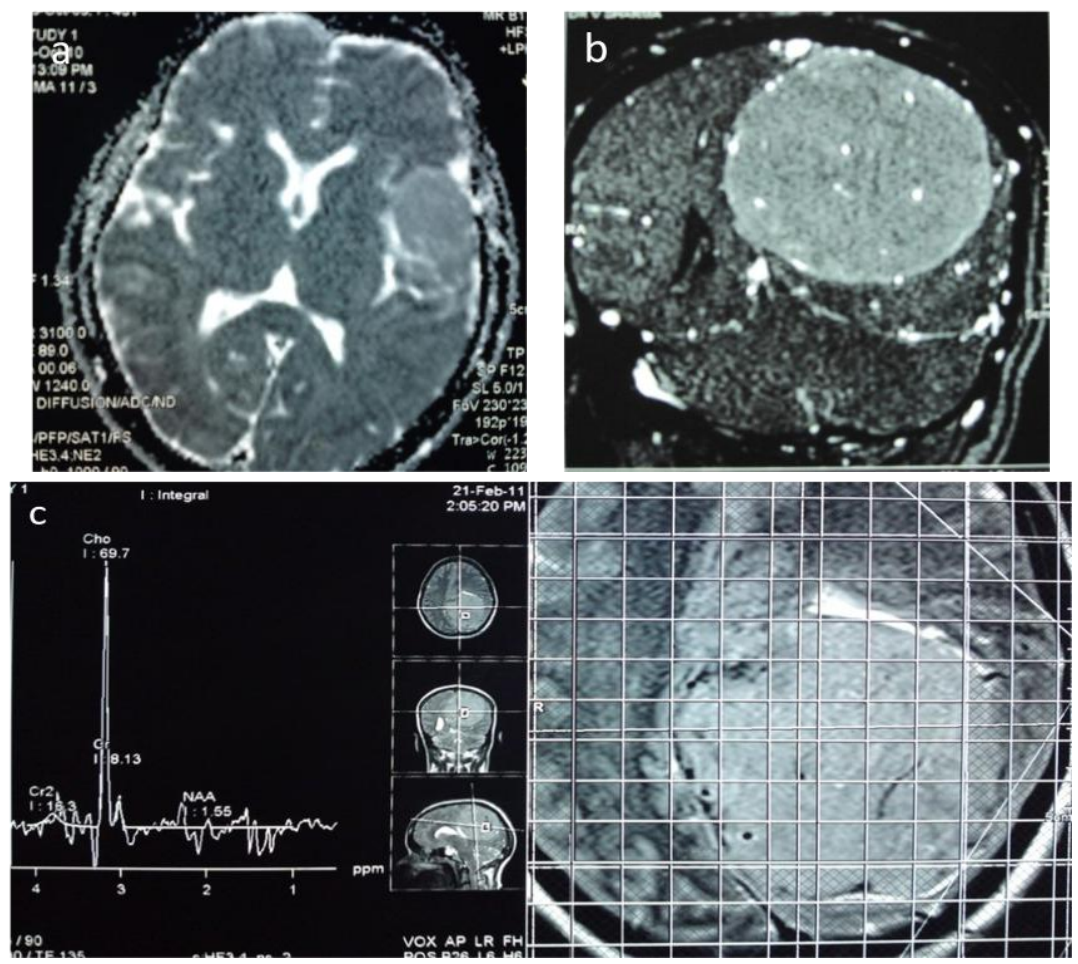

Fig 6: Advanced imaging features Fig a) axial ADC map showing diffusion restriction, Fig b) MR 2D TOF MR angiogram showing internal macrovascularity, Fig c) MRS showing choline peak.

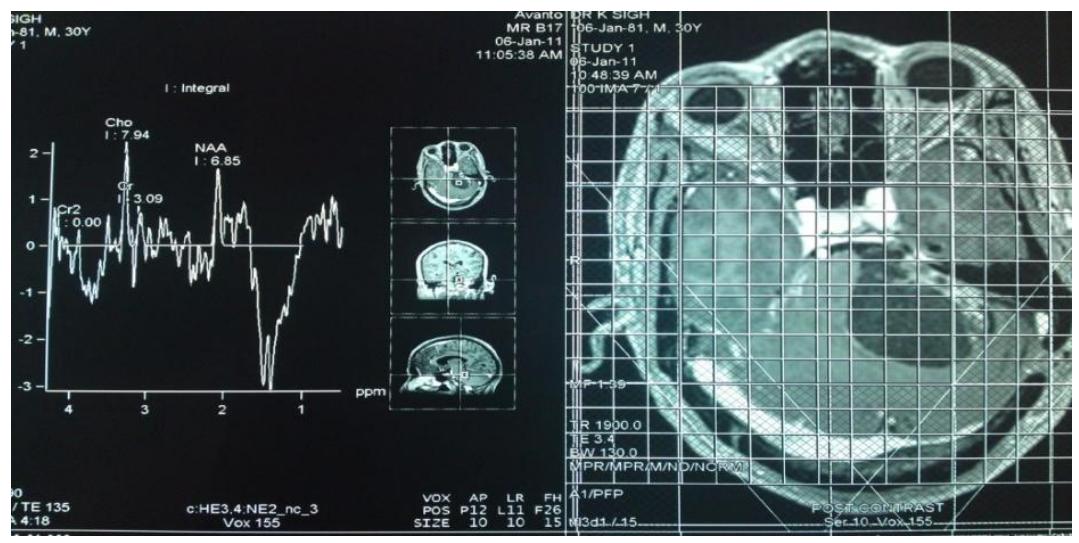

Fig 7: Imaging features of cystic meningioma MR spectroscopy of left cystic meningioma showing choline peak and inverted alanine peak at 1.45ppm.
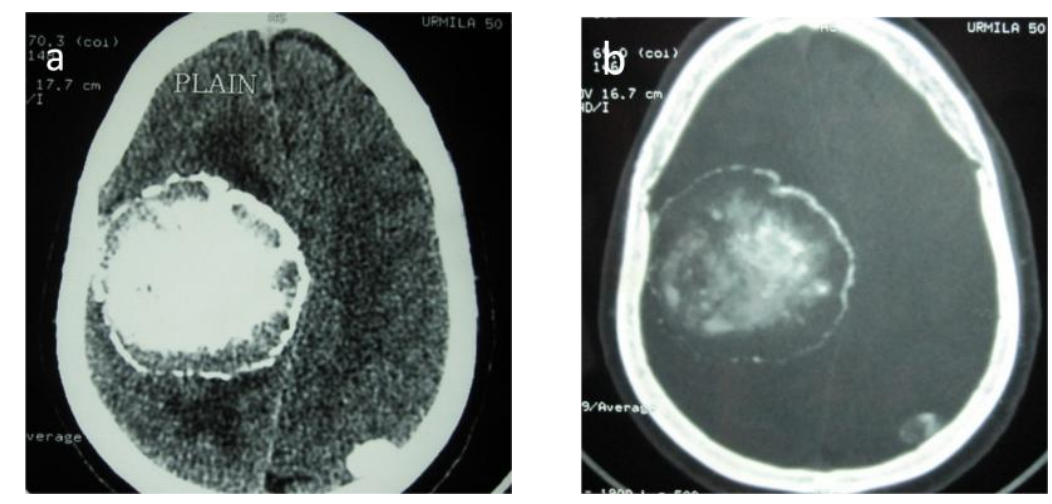

Fig 8: Atypical meningioma calcification pattern on NCCT. a) Axial NCCT b) Axial NCCT bone window settings showing dense central calcification foci with peripheral rim calcification. 
Meningiomas are mostly benign tumours originating from non-neuroepithelial progenitor cells, the arachnoid cap cells. Arachnoidal cap cells form a morphologically distinct and highly metabolic active subgroup of arachnoidal cells, are involved in the resorption of cerebrospinal fluid. They are situated at the apex of Pacchionian bodies and exposed to venous blood flow, often within a dural sinus. $^{2}$ Meningiomas present clinically by causing focal or generalized seizure disorders, focal neurological deficits, or neuropsychological decline. An estimated $2-3 \%$ of the populations have an incidental asymptomatic meningioma, and in autopsy studies $8 \%$ of these are multiple. ${ }^{3}$

Established risk factors for the development of meningiomas include deletion in neurofibromatosis type 2 gene, ionizing radiation, head injury. It has been demonstrated that approximately two thirds of all meningiomas express progesterone receptors on their cell membranes, occurring more frequently in female patients; however, the role of sex hormones in the genesis of meningiomas is yet not clarified. Schneider et al. postulated that diabetes mellitus was associated with meningiomas, as well as arterial hypertension in females. ${ }^{2}$

Excluding those in spinal locations, which constitute approximately $12 \%$ of all meningiomas, intracranial and juxtacranial meningiomas arise in the following locations in descending order of frequency: convexity (lateral hemisphere) (20\%-34\%); parasagittal (medial hemisphere) (18\%$22 \%$ ) (includes falcine meningiomas (5\%), which are located below the superior sagittal sinus and usually extend to both sides); sphenoid and middle cranial fossa (17\%-
25\%); frontobasal (10\%); posterior fossa (9\%-15\%), including the tentorium cerebelli (2\%-4\%), cerebellar convexity (5\%), cerebellopontine angle (2\%-4\%), and clivus $(<1 \%)$; intraventricular $(2 \%-5 \%)$; orbital $(<$ $1 \%-2 \%)$; and ectopic $(<1 \%){ }^{4}$ Because complete surgical resection is the definitive treatment for meningiomas, the single most important feature regarding therapy is tumor location, as it substantially affects surgical accessibility. Consequently, it is important to recognize the potential atypical locations of these neoplasms to ensure both proper diagnosis and treatment. ${ }^{5}$

\section{Typical imaging appearances:}

Plain films:

The role of plain film imaging in the investigation of meningiomas has been superseded by other techniques. Plain films are normal in the majority of cases although they may demonstrate hyperostosis, calcification, and osteolysis associated with the tumours. ${ }^{6}$

On non-contrast CT, meningiomas appear as unilobular, homogeneous hyperdense masses in relation to brain parenchyma. After the administration of contrast medium, they show intense and usually homogeneous enhancement. Calcification is seen on CT in $20-27 \%$ of meningiomas. ${ }^{4}$ It is usually microscopic or punctuated, but may be large, conglomerate, peripheral or central. Hyperostosis of the adjacent calvarium or skull base may be seen in 18-50\%. Bone destruction is an uncommon feature found in approximately $3 \%$ of cases.

On magnetic resonance (MR) images, the typical features of meningiomas include a 
unilobar mass with sharply circumscribed margins and inward displacement of the cortical gray matter. ${ }^{7}$

On MR images obtained without contrast material enhancement, meningiomas are characteristically hypointense to isointense with Ti-weighted pulse sequences and isointense to hyperintense with T2-weighted pulse sequences. ${ }^{8}$ On MR images obtained with gadolinium, the mass homogeneously enhances. Meningiomas usually demonstrate a prominent and persistent blush on angiograms, and the most frequent calvarial change is hyperostosis of the adjacent skull, which may be seen on plain radiographs, as well as on CT and MR images.

Diffusion-weighted MRI, perfusion MRI and proton MR spectroscopy may be used in the diagnosis of meningiomas. On diffusionweighted MR images the atypical and malignant meningiomas tend to be markedly hyperintense and exhibit marked decreases in the diffusion constant (DAV) or ADC values when compared with normal brain parenchyma, while the benign meningiomas have a variable appearance on diffusionweighted images and tend to have higher (DAV) values compared with normal brain. On perfusion MRI the meningiomas are hyperperfused. In MR spectroscopy, the meningiomas are characterized by the presence of alanine, low creatine and $\mathrm{N}$ acetyl-aspartate, high choline and glutamine and absence or low quantities of lipids. ${ }^{9}$

\section{Angiography:}

Meningiomas are usually very vascular tumours, which demonstrate a prominent tumour blush and delayed "washout" on catheter angiography. Theyare usually supplied by meningeal branches of the external carotid artery, the internal carotid artery and/or the vertebral artery. Additional supply may also arise from pial vessels. Meningiomas may en-case or displace major vessels, and may occlude large veins and cerebral venous sinuses. Preoperative identification of these features is essential to minimize the risk of intra-operative haemorrhage or postoperative infarction due to vascular damage. ${ }^{10}$

\section{Atypical Imaging Features:}

The imaging features of meningiomas may be atypical in terms of signal characteristics, tumour location or behaviour. However, atypical imaging appearances do not necessarily predict atypical histology. Atypical appearances include:

\section{- Cystic Meningioma / Hypodensity}

Cysts associated with meningiomas are uncommon. The incidence may vary from 1.6-10\%. ${ }^{11}$ Cysts associated with meningiomas may be divided into intratumoral or peritumoral cysts depending on whether the cyst walls are lined by meningothelial cells. Intratumoral cysts are rare and arise mainly from degenerative and secretory changes within the tumor. Fortuna et al ${ }^{12}$ believe that intratumoral cysts develop because of microcystic degeneration, ischemic necrosis, and/ or hemorrhage. This may be in addition to secretory changes within the tumor. Peritumoralcysts are large, contain xanthochromic fluid with a high protein content, and are lined by fibrillary astrocytes and their processes-a glial response to the presence of a meningioma. $^{13}$ 
The most frequent location of cystic meningiomas is on the cerebral convexity; the parasagittal region is the second most frequent location. CT scans often show mixed density masses, which are isodense on unenhanced scan with hypodense areas. On contrast enhancement, the isodense part of the tumors is enhanced. On CT scans, peritumoral cysts may be seen as a zone of diminished density of variable width surrounding the tumor. ${ }^{11}$ Currently, MRI especially with gadolinium enhancement, is the preferred mode, since this is able to distinguish cyst wall invaded by tumor cells (type 2) from cyst wall composed of gliotic tissue without tumor infiltration (type 3 ). ${ }^{14}$

\section{- Lipomatous Meningioma:}

Lipomatous meningioma, also known as lipomeningioma or lipoblastic meningioma is a rare entity. Thirty-two cases have been described in the literature. ${ }^{15}$ According to AlMefty ${ }^{16}$, it is characterized by a transformation of meningothelial cells into adipocytes. Radiologically the tumor is usually hypodense on CT and shows high intensity on T1-weighted and T2-weighted MRI, and the high intensity area on T1weighted MRI is changed to a low intensity area on fat-suppressed T1-weighted imaging. ${ }^{3,5-8,10-24}$ A true benign 'lipomeningioma' presents adipose tissue elements admixed with the meningioma. The lipomatous meningioma usually presents whorls consisting of meningothelial cells with only one triglycerides droplet, and a peripherally displaced nucleus. ${ }^{17}$

\section{- Peritumoral Edema:}

Peritumoral edema is present in at least half of the cases of meningioma, and it may be present in varying degrees and in an unpredictable fashion. The mechanism by which a meningioma produces peritumoral edema is not fully elucidated. ${ }^{18}$ The cause of intraaxialperitumoralvasogenic edema associated with meningiomas is controversial. Some theories implicate active fluid production (secretion or excretion) by the tumor, with "flow" through the thinned contiguous cortex. Others have suggested that the tumor injures the brain mechanically (by means of direct compression) or ischemically (from parasitization of the cortical arteries, compression of the cortical veins, or frank involvement of the dural sinuses). Most likely, the edema is caused by a combination of different mechanisms. ${ }^{19}$

\section{- Ring Enhancement:}

Meningiomas are usually fairly homogeneous masses, with homogeneous enhancement. However, they may have an atypical ringed appearance, rather than occur as a solid mass. The peripheral enhancement represents the normal pattern for viable meningeal neoplasms, and the center is an avascular or necrotic region. The causes for the central non-enhancing zone vary and include bland tumor infarction, necrosis in aggressive histologic variants, and true cyst formation from benign fluid accumulation. ${ }^{20}$

\section{Classification and Grading:}

Most meningiomas are benign and correspond to WHO grade I. Certain histological subtypes or meningiomaswith specific combinations of morphologic parameters are associated with less favourable clinical outcomes and correspond to WHO grades II (atypical) and III (anaplastic or malignant). 
Meningiomas grouped by likelihood of recurrence and grade by $\mathrm{WHO}^{21}$

Meningiomas with low risk of recurrence and aggressive growth

Meningothelial

meningioma

Fibrous (fibroblastic)

meningioma

Transitional (mixed)

meningioma

Psammomatous

meningioma

Angiomatous meningioma

Microcystic meningioma

Secretory meningioma

Lymphoplasmacyte-rich

meningioma

Metaplastic meningioma

Meningiomas with greater likelihood

of recurrence and/or aggressive behaviour

Chordoid meningioma $\quad$ WHO grade II

Clear cell meningioma

(intracranial)

Atypical meningioma

Papillary meningioma

Rhabdoid meningioma

Anaplastic (malignant)

meningioma

WHO grade II

WHO grade II

WHO grade III

WHO grade III

WHO grade III

\section{Histopathology:}

Meningiomas exhibit a wide range of histologic appearances. ${ }^{23}$ Of the subtypes in the WHO classification, meningothelial, fibrous and transitional meningiomas are the most common. The majority of subtypes behave in a common clinical manner, but four histologic variants, falling into the grade II and III categories, are far more likely to recur and follow a more aggressive clinical course including metastasis.

\section{WHO Criteria For Meningioma Grading} 22

\section{Benign meningioma (WHO grade I)}

-Histological variant other than clear-cell, chordoid, papillary, or rhabdoid

- Lacks criteria of atypical and anaplastic meningioma

Atypical meningioma (WHO grade II)

(any of three criteria)

-Mitotic index $\geq$ four mitoses/ten highpower fields (HPF)

-At least three of five parameters:

-Increased cellularity

-High nuclear/cytoplasmatic ratio (small cells)

-Prominent nucleoli

-Uninterrupted patternless or sheet-like growth

-Foci of spontaneous necrosis (i.e, not induced by embolisation or radiation)

- Brain invasion

Anaplastic (malignant) meningioma

(WHO grade III) (either of two criteria)

-Mitotic index $\geq 20$ mitoses/10 HPF

- Anaplasia (sarcoma, carcinoma, or melanoma-like histology)

\section{Meningothelial Meningioma:}

Meningothelialmeningiomas

are histologically composed of characteristic uniform tumour cells that form lobules surrounded by thin collagenous septae. Within the lobules, epithelioidtumour cells have fuzzy ill-defined cell borders that resemble a syncytium. Characteristic nuclear changes include clear spaces (that seem empty of karyoplasm) and rounded eosinophilic cytoplasmic protrusions, referred to as pseudoinclusions. ${ }^{24}$ 

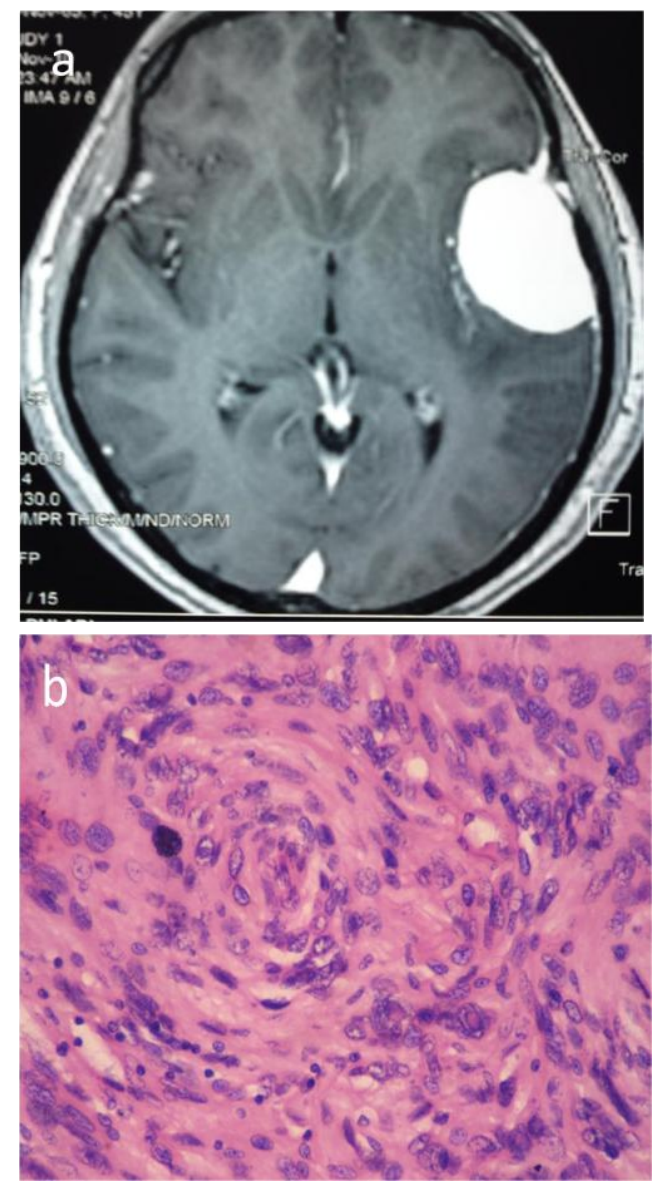

Fig 9: Meningothelial meningioma. Fig a) T1W post contrast MR imaging showing homogenous intensely enhancing dural based extra axial mass lesion in left temporal region Fig b) histopathology of thesame showing typical intranuclear inclusions with syncytial appearance of cells.

\section{Fibrous (Fibroblastic) Meningioma:}

Fibrous meningiomas are mainly composed of spindle-shaped cells that resemble fibroblasts and form intersecting fascicles embedded in a collagen-rich and reticulinrich matrix. ${ }^{24}$ Fibroblastic and transitional meningiomas tend to be hypointense or isointense relative to the cerebral cortex, and meningothelial, malignant and angioblasticmeningiomas, on the other hand, tend to be hyperintense on T2-weighted images. $^{25}$

\section{Transitional (Mixed) Meningioma:}

Transitional (mixed) meningiomas combine features of both subtypes and usually present with extensive whorl formation, wherein tumour cells wrap around each other forming concentric layers. The latter have a tendency to hyalinise and calcify to form the characteristic concentric calcifications known as psammoma ("sand-like", based on their gritty, gross appearance) bodies. ${ }^{24}$

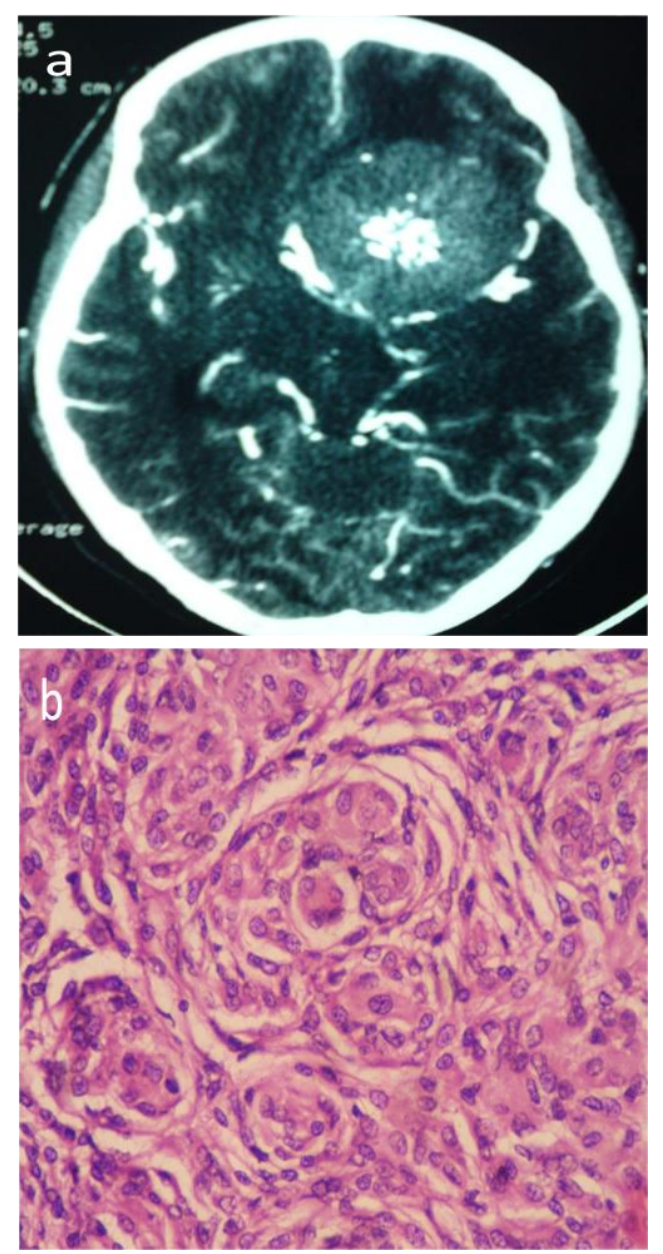

Fig 10: Transitional meningioma. Fig a) axial sphenoid region mass showing displaced vessals surrounding it and central coarse calcification Fig b) histopathology of the same showing showing extensive whorl formation. 

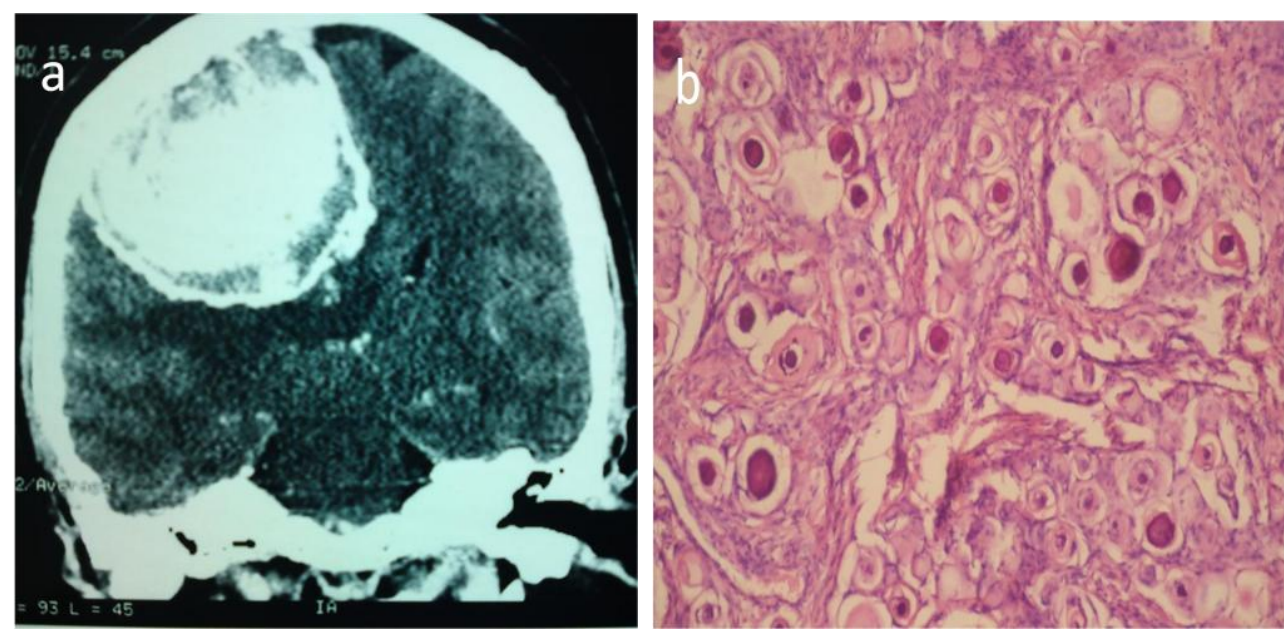

Fig 11: Psammomatous meningioma. Fig a) coronal CECT showing densely calcified and apparently ossified meningioma in right parietal region. Fig b) histopathology of the same showing numerous calcified psammoma bodies and inconspicuous meningothelial component.
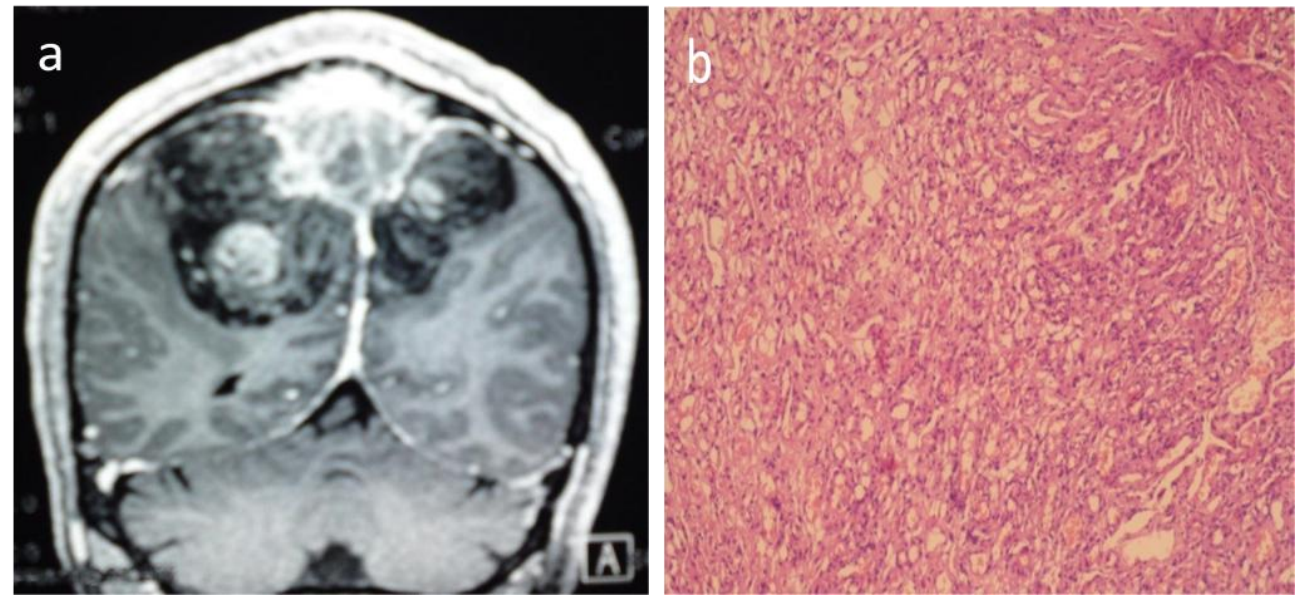

Fig 12: Angiomatous meningioma Fig a) coronal post contrast T1W MR imaging showing intensely enhancing sagittal sinus mass with radiating vessels with peripheral hemorrhagic foci Fig b) Histopathology of the same showing excessive vascularization interspersed with small meningothelial cells.

\section{Psammomatous Meningioma:}

This designation is applied to meningiomas containing a predominance of psammoma bodies over that of the tumour cells which give rise to them. They often become confluent, forming irregular calcified masses and occasionally bone. The neoplastic cells of this variant usually have a transitional appearance with whorl formation. Some tumours are almost completely replaced by psammoma bodies, intervening meningothelial cells being hard to find. Psammomatousmeningiomas characteristically occur in the thoracic spinal region and usually in middle-aged women. ${ }^{21}$

\section{Angiomatous Meningioma:}

Angiomatousmeningiomas have the histological and clinical features of benign meningioma in which the blood vessels 
components

exceed

$50 \%$.

Angiomatousmeningiomas are rare tumors and constitute $2.1 \%$ of all meningiomas.Angiomatousmeningiomas have some specific radiographic features. Because of the great amount of blood vessels, bleeding within the tumor mass is usual. Peritumoral edema is observed very often (although they belong to WHO grade I). Angiomatousmeningiomas also show isointensity or hyperintensity to the cerebral cortex on MRI. Short extension of contrast enhancing tissues along the dura mater (dural tail) is also a valuable diagnostic feature. $^{26}$ Martin et al. classified angiomatous meningioma into two patterns based on diameter of vessels as $>50 \%$ of vessels having larger than $30 \mu \mathrm{m}$ in diameter and microvascular subtype in which $>50 \%$ of vessels were smaller than $30 \mu \mathrm{m}$ in diameter. It is the microvascular pattern which can be confused with hemangioblastoma. Angiomatous meningioma can have foamy cells which are related to leakage of plasma lipids across thin vessel wall. All the meningiomas which are entirely hemangioblastic cannot be distinguished from hemangioblastoma except by its attachment to dura, immunohistochemical markers, and electron microscopy. ${ }^{27}$

\section{Microcystic Meningioma:}

It accounts for $1.6 \%$ of intracranial meningiomas. MRI studies on microcysticmeningiomas are scarce. Paek et al. ${ }^{28}$ reported MRI characteristics of 16 cases with micro-cystic meningiomas. They concluded that characteristicMRI findings of microcysticmeningiomas show low signal intensity on T1-weighted images, high signal intensity on T2-weighted images and high incidence of peritumoral edema. This variant is characterized by cells with thin, elongate processes encompassing microcysts containing pale, eosinophilic mucinous fluid. Pleomorphic cells may be numerous, but microcysticmeningiomas are typically benign. $^{21}$

\section{Atypical Meningioma:}

Atypical meningioma accounts for about $4.7 \%$ to $7.2 \%$ of all kinds of meningiomas, which is invasive with a relatively high recurrence and mortality. The typical course of atypical meningioma (6-10 months) is shorter than that of benign meningioma (2-4 years). Atypical meningiomas are characterized by uneven and partially invasive growth, irregular edges, and lobulated or mushroom-like protuberances. Plain imaging scans show uneven density or signal intensity, and a minority of tumors have necrosis or cystic degeneration appearing as low density. Calcification is less frequently observed on imaging. Enhancement scans reveal irregular edges, uneven enhancement, and uneven internal structure. Peritumoral edema may occur depending on the location of the tumor. The "dural tail" sign is short and irregular. In addition, damage to the skull and dura mater/venous sinus is evident. ${ }^{29}$

\section{Secretory Meningioma:}

These tumours have a marked female predominance (male: female ratio of 9:1) and preferentially involve thefrontal meninges and sphenoid ridge. On clinicoradiologic evaluation, this subtype may present with PTBE giving an ominous picture. The tumour represents a highly 

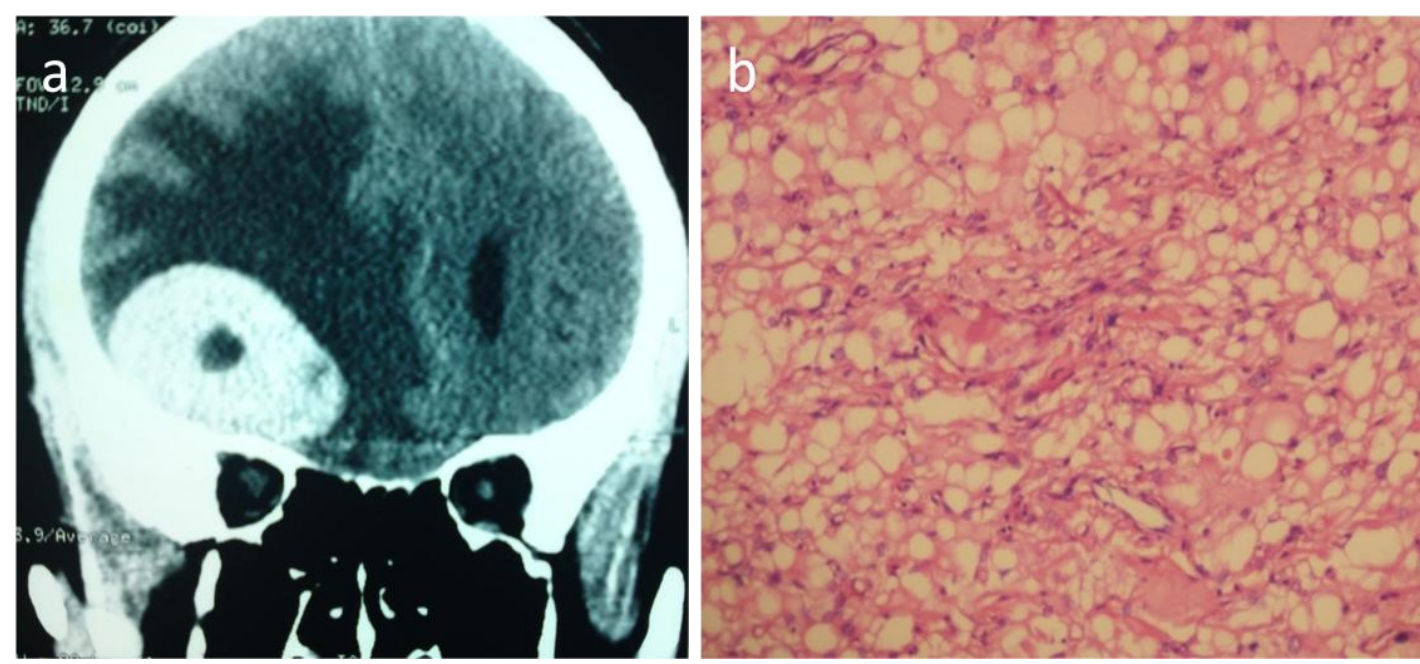

Figure 13:Microcystic meningioma Fig a) coronal CECT showing intensely enhancing globular extra axial mass lesion in right temporal region showing internal hypodense foci with extensive surrounding brain edema, Fig b) Histopathology of the same showing intercellular microcystic spaces.
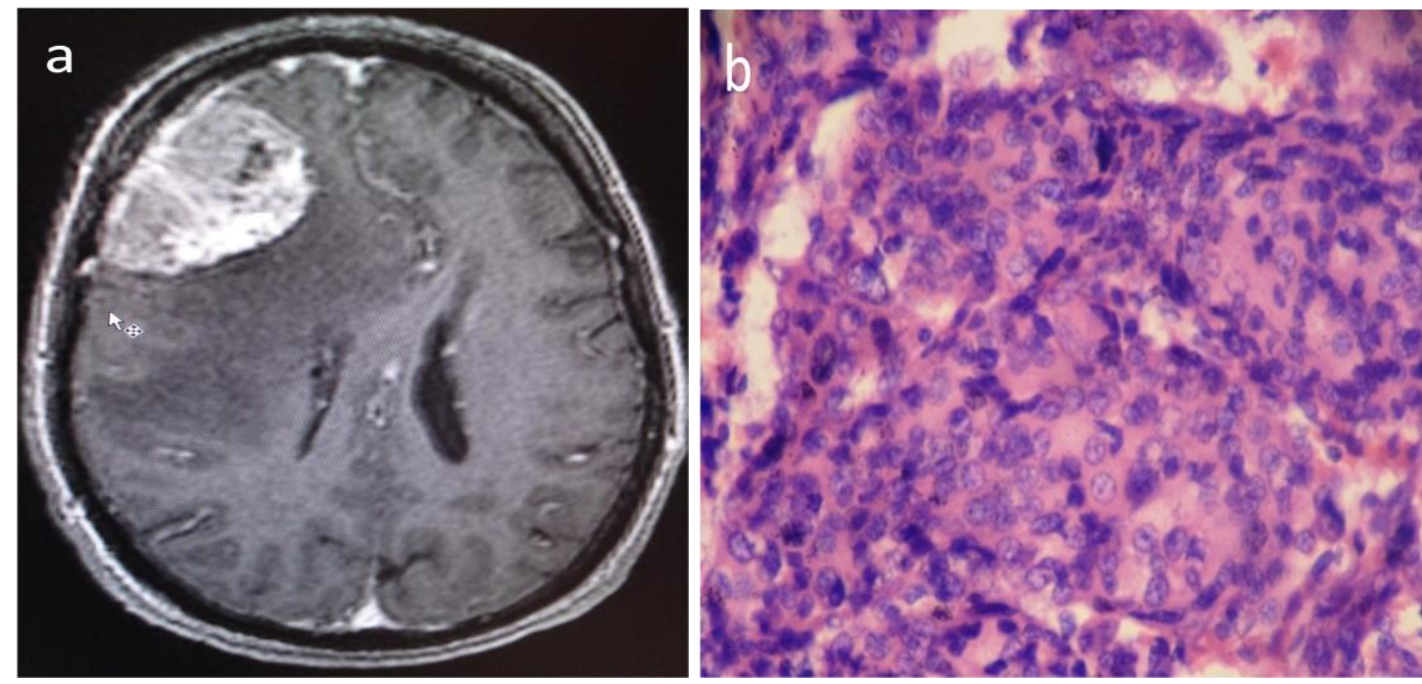

Fig 14: Atypical meningioma Fig a) axial post contrast T1W imaging showing intensely enhancing heterogenous extra axial mass with irregular in right frontal region showing internal hypointense foci with extensive surrounding brain edema and mass effect, Fig b) Histopathology of the same showing Patternless sheet like growth, with hypercellularity, presence of small cells and mitosis with foci of necrosis elsewhere.

vascular meningothelial meningioma with glandular differentiation and perivascular arrangement of cells. It is marked by the presence of small, round, eosinophilic, strongly PAS positive, diastase-resistant and 'pseudopsamomma' bodies.MR signal intensity features are useful information in the characterisation of meningiomas. ${ }^{30}$
On T1-weighted images, meningiomas are isointense $(62.5 \%)$ or hypointense $(37.5 \%)$ relative to the cerebral cortex. On T2weighted images, the tumours are isointense $(51 \%)$ or mildly hyperintense $(40 \%) .{ }^{31}$

\section{Chordoid Meningioma:}

The term "chordoidmeningiomas" was first coined by Kepes et al. $^{32}$ as a 
histopathological classification of tumors removed in seven patients (aged 8-19 years) with Castleman's syndrome. CM was described as an independent entity in children with hematological involvement and has been recognized as a peculiar meningioma in children with an inflammatory syndrome. $\mathrm{CM}$ represents between 0.5 and $1.0 \%$ of all meningiomas, and it is frequently located in the supratentorial region. ${ }^{33}$

\section{Clear Cell Meningioma:}

Clear cell meningioma, also referred to as glycogen-rich meningiomas, is an uncommon variant of meningioma, corresponding to WHO grade II. They represent only $0.2 \%$ of all meningiomas, and may behave aggressively with local recurrence and cerebrospinal fluid metastasis. Clear cell meningiomas usually affect younger patients and more frequently occur in the spinal and cerebellopontine region. Histologically, classical CCM is composed of polygonal cells with clear, glycogen-rich cytoplasm and prominent blocky perivascular and interstitial collagen. The sheets of glycogenated cells have an abundant clear cytoplasm with round, uniform, bland-appearing nuclei [clear cell meningioma]. Immunohistochemistry shows that tumor cells are positive for vimentin and epithelial membrane antigen. ${ }^{34}$

The tumour is isointense with the parenchyma on T1 and T2 weighted MRI. The MRI features of CCM are not much different from the other meningiomas. On T1 and T2 weighted MRI the tumour is isointense with the parenchyma and homogeneously enhances after gadolinium injection. $^{35}$

\section{Papillary Meningioma:}

Papillary meningioma (PM) is an aggressive histological variant of meningioma, which accounts for $1.0-2.5 \%$ of all meningiomas. PM are frequently seen in the supratentorial compartment though rare locations like posterior fossa, jugular foramen and occulomotor nerve have been described. ${ }^{36} \mathrm{It}$ is defined by the presence of a perivascular pseudopapillary pattern comprising the majority of the tumour. ${ }^{21}$

\section{Rhabdoid meningioma \\ Anaplastic (Malignant) Meningioma:}

Anaplastic or malignant meningiomas (WHO Grade III) represent the most rare but aggressive subtype, accounting for 1-3\% of all intracranial meningiomas. The genetic alterations associated with anaplastic meningiomas are complex, some of which are shared with atypical meningiomas.

Differentiating between malignant and benign meningiomas before surgery is important for both treatment planning Sand the prognosis appraisal. Although meningiomas do have some identifiable imaging features on conventional MR images, no special feature has been found to be reliable in predicting tumor grade. Perfusion MR imaging reflects the characteristics of the regional blood supply, an important biological marker of tumor grade and prognosis [Perfusion MR imaging for differentiation]. One study reports the use of six imaging features as a means of distinguishing Grade I from Grade II/III meningiomas: (1) intratumoral cystic change; (2) hyperostosis of the adjacent skull; (3) bony destruction; (4) extracranial tumor extension through the skull base; (5) 
arterial encasement; and (6) peritumoral brain edema. ${ }^{37}$

There are, however, some CT or MRI trends that point in favor of malignant meningioma: 1) the absence of visible calcium aggregates; 2) "mushrooming" or the presence of a prominent pannus of tumor extending well away from the globoid mass; 3) nonhomogeneous enhancement ; 4) necrosis ; and 5) presence of in-distinct tumor margins. If angiography is performed, arteriovenous shunting is a feature that suggests malignancy.

The proliferative potential of tumors can be quantitated, using bromodeoxyuridine, KI67, MIB-1 and proliferating cell nuclear antigen (PCNA) labeling index, and this information helps in predicting the clinical behavior of tumors and the need for treatment. $^{38}$

\section{Conclusion:}

In view of the observed evidence, it was concluded that understanding the classification, pathology and imaging appearance meningioma are essential for treatment planning. $\mathrm{CT}$ and $\mathrm{MR}$ imaging play indispensable role in the localization \& characterization of these tumors, and MR have virtually yielded its position of dominance in characterizing these tumors.

\section{References:}

1. Russell DS, Rubinstein U. Pathology of tumors of the nervous system. 5th ed. Baltimore: Williams \& Wilkins, 1989; 449-483.

2. Christine M, Marco H, Karl R, et al. Meningioma. Critical Reviews in
Oncology/Hematology $\quad 2008 ; 67: 153-$ 171.

3. Ian RW, Colin S, Parthiban N, Donald C. Meningiomas. Lancet 2004;363: 1535-43.

4. Rohninger M, Sutherland GR, Louw DF, Sima AAF. Incidence and clinicopathological features of meningioma. J Neurosurg 1989;71:665672.

5. Michael PB, Peter CB, James G. Smirniotopoulos: Typical, Atypical, and Misleading Features in Meningioma. RadioGraphics 1991;11:1087-1106.

6. Ricci PE. Imaging of adult brain tumours. Neuroimaging Clin $\mathrm{N}$ Am 1999;9:651-69.

7. Bradac GB, Ferszt R, Kendall BE. Cranial meningiomas. Berlin: SpringerVerlag 1990;1-128.

8. Zimmerman RD, Fleming CA, SaintLouis LA, Lee BCP, Manning JJ, Deck MDF. Magnetic resonance imaging of meningiomas. AJNR 1985;6:149-157.

9. Majos C, Alonso J, Aguilera C et al. Proton magnetic resonance spectroscopy (1HMRS) of human brain tumors: assessment of differences between tumour types and its applicability in brain tumour categorization. EuRadiol 2003;13:582-591.

10. Buetow MP, Buetow PC, Smirniotopoulos JG. Typical, atypical, and misleading features in meningioma. RadioGraphics 1991;11:1087-1106.

11. Meng L, Yuguang L, Xingang L, Shugan Z, Chengyuan W. Cystic meninigioma. Journal of Clinical Neuroscience 2007;14:856-859.

12. Fortuna A, Ferante L, Acqui M, Guglielmi G, Mastronardi L. Cystic meningioma. ActaNeurochirur (Wien) 1988;90:23-30. 
13. Sridhar K, Ravi R, Ramamurthi B, Vasudevan MC. Cystic Meningiomas. SurgNeurol 1995;43:235-9.

14. Prabal D, Hirdesh S, Harjinder SB. Cystic angiomatous meningioma in the cerebellopontine angle mimicking hemangioblastomas. J Can Res Ther 2010;6:560-3.

15. Sophie CC, Stephane K, Nicolas W, Catherine P, Jean A. Lipomatous meningioma: report of 2 cases and review of the literature. Surgical Neurology 2008;69:398-402.

16. Al Mefty O. Meningiomas. New York7 Raven Press; 1991. p. 11

17. Giuseppe M, Renato S, Maria LD, Enrico D. An unusual case of lipoblastic meningioma of the falxcerebri. Clinical Neurology and Neurosurgery 2000;102:180-185.

18. Kyung-Jin L, Won-Il J, Hyung-Kyun R, et al. Peritumoral brain edema in meningiomas: correlations between magnetic resonance imaging, angiography, and pathology. Surgical Neurology 2008;69:350-355.

19. Michael PB, Peter CB, James GS. Typical, Atypical, and Misleading Features in Meningioma. RadloGraphics 1991;11:1087-1106.

20. Worthington C, Caron J, Melanson D, Leblanc R. Meningioma cysts. Neurology 1985;35:1720-1724.

21. Perry A, Louis DN, Scheithauer BW, Budka H, von Deimling A.WHO Classification of Tumours of the Central Nervous System. Lyon: IARC Press, 2007:10:164-172.

22. Kleihues $P$, Cavenee WK, International Agency for Research on Cancer. Pathology and genetics of tumours of the nervous system. Lyon: IARC Press, 2000.
23. Burger PC, Scheithauer BW, Vogel FS (1991). Surgical pathology of the nervous sys-tem and its coverings. Churchill Livingstone: London.

24. Markus JR, Arie P, Guido R. Histological classification and molecular genetics of meningiomas. Lancet Neurol 2006;5:1045-54.

25. Chen TC, Zee CS, Miller CA, et al. Magnetic resonance imaging and pathological correlates of meningiomas. Neurosurgery 1992;31:1015-1021.

26. Chaushev N, Topalov N, Milanov I. A case report of Angiomatous meningioma. J Clin Med 2010;3(3):6063.

27. Shalinee R, Aarthi R, Sarah K. Angiomatous meningioma: A diagnostic dilemma. IJPM 2008;51(1):53-55.

28. Paek SH, Kim SH, Chang $\mathrm{KH}$ et al. Microcysticmeningiomas: radiological characteristics of 16 cases. ActaNeurochir (Wien) 147:965-972.

29. Shu-qing Y, Ji-sheng W, Nan J, Wei L, $\mathrm{Ke}$ Q. Clinical characteristics and therapeutic strategies of atypical meningioma. Chin Med J 2011; 124(7):1094-1096.

30. Lakhtakia R, Ramdas GV, Alam A, Mehta A. Secretory Meningioma Mimicking Malignancy. MJAFI 2008; 64:82-83.

31. Shunji N, Takato M, Satoshi S, Kyoko H, Masashi F. Secretory meningioma: clinicopathologic features of eight cases. Journal of Clinical Neuroscience 2001; 8(4),335-339.

32. Kepes JJ, Chen WY, Connors MH, Vogel FS. "Chordoid" meningeal tumors in young individuals with peritumoral lymphoplasmacellular infiltrates causing sys-temic manifestation of the 
Castleman syndrome. A report of seven cases. Cancer 62:391-406.

33. Shuichi M, Kuniyuki O, Hando H, et al. Chordoid meningioma. A Case Report. Pathol. Res. Pract. ;197:515-518.

34. Whal L, Kee HC, Gheeyoung C, et al. MR Imaging Features of Clear-Cell Meningioma with Diffuse Leptomeningeal Seeding. AJNR Am J Neuroradiol 2000;21:130-132.

35. Kayhan K, Ertugrul C, Haydar U, et al. Clear cell meningioma: case report and literature review. Journal of Clinical Neuroscience 2003;10(2).
36. Singh A, Sarvjot V, Sharma S, Karam Chand. Papillary meningioma: a rare but distinct variant of malignant meningioma. Diagnostic Pathology 2007;2:3.

37. Simon H, Peter C, Jeffrey NB. A review of malignant meningiomas: diagnosis, characteristics, and treatment. J Neurooncol 2010;99:433-443.

38. Asdrubal F, José AN, Leila C, et al. Anaplastic Meningioma. Arq Neuropsiquiatr 2001;59(4):939-943. 